\title{
Association between Hypertension and Immunosuppression in SARS-CoV-2 Infection
}

\author{
Diego Chambergo-Michilot ${ }^{1 \star}$, Isidro Percy Chambergo Campos ${ }^{2}$
}

\author{
${ }^{1}$ Universidad Científica del Sur, Lima, PERU \\ ${ }^{2}$ Universidad Tecnológica del Perú - Carrera de Contabilidad, Lima, PERU \\ *Corresponding Author: diegochambergomichilot@hotmail.com
}

Citation: Chambergo-Michilot D, Chambergo Campos IP. Association between Hypertension and Immunosuppression in SARS-CoV-2 Infection. Electron J Gen Med. 2021;18(4):em297. https://doi.org/10.29333/ejgm/10867

\section{ARTICLE INFO}

Received: 1 Mar. 2021

Accepted: 16 Apr. 2021

\begin{abstract}
Coronavirus disease 2019 (COVID-19) has caused more than 32 million cases and almost a million deaths. Recent reviews have evidenced the role of hypertension in prognosis, nevertheless, its association with immunosuppression in COVID-19 context has not been studied. It was performed a cross-sectional analysis of a large Mexican population with the infection $(n=681890)$. Prevalence of immunosuppression and hypertension was $1.10 \%$ and $19.50 \%$, respectively. The adjusted model evidenced that hypertension was significantly associated with immunosuppression (odds ratio $=1.18,95 \% \mathrm{Cl}=1.11-1.25$ ). Further research in pathways that justify the association between hypertension and immunosuppression in COVID-19 patients is recommended.
\end{abstract}

Keywords: hypertension, COVID-19, severe acute respiratory syndrome coronavirus 2, Mexico, public health
Dear editor,

Up to the date, coronavirus disease 2019 (COVID-19), which is caused by the severe acute respiratory syndrome coronavirus 2 (SARS-CoV-2), has caused more than 32 million cases and almost a million deaths [1]. Moreover, several studies have proposed the role of non-communicable diseases (NCDs) in evolution and prognosis of COVID-19.

A previous meta-analysis reported that hypertension is one of the most frequent NCDs in infected patients, moreover, it was significantly associated with severe COVID-19 [2]. Regarding biological plausibility, it is postulated that coronaviruses down-regulate the pulmonary angiotensinconverting enzyme 2 receptors, which leads to a subsequent accumulation of angiotensin II [3]. This accumulation may contribute to pulmonary damage, and increased blood pressure [3]. Indeed, results from a recent systematic review suggested that anti-hypertensive medication reduces COVID19 mortality [4]. It is known that several NCDs are related to immunosuppression, which worsens COVID-19 severity, nevertheless, the association between it and hypertension has not been established in the population of interest. Therefore, we aimed to identify this association in the Mexican population.

It was performed a cross-sectional analysis of the database released by the Secretaría de Salud de México, which covered the period ending on May 18, 2020. Analyses in this paper were limited to this date. The database was freely available at https://bit.ly/308Yu4y, and it registered variables of patients who were tested for SARS-CoV-2.

The dependent variable was immunosuppression (yes or no). It is defined as the presence of low markers of immune response. The independent variable was the existence of hypertension (yes or no). Two logistic regression models

(unadjusted and adjusted) were performed to identify the association between both variables. The second model was adjusted for all potential confounders: age, sex, diabetes, chronic obstructive pulmonary disease, obesity, pneumonia, smoking history, and other cardiovascular diseases. Analyses were done using Stata v.16 (College Station, TX: StataCorp LLC).

Data from 1048575 patients was originally reported in the database. Prevalence of positive SARS-CoV-2 infection was $65.24 \%(n=684113)$. After excluding missing data in both dependent and independent variables, 681890 patients with positive infection were included in this study.

Male sex accounted for $52.09 \%$. The mean age was 44.77 (standard deviation= 16.65). Prevalence of immunosuppression was $1.10 \% \quad(n=7 \quad 485)$. Moreover, hypertension accounted for $19.50 \%(n=132974)$.

It was found a significant association between hypertension and immunosuppression in patients with positive SARS-CoV-2 both in the unadjusted [OR=2.13, 95\% confidence interval $(\mathrm{Cl})=2.03-2.24]$ and adjusted models (OR=1.18, 95\% Cl=1.11-1.25) (Table 1).

Table 1. Association between hypertension and immunosuppression in patients with positive SARS-CoV-2

\begin{tabular}{|c|c|c|c|}
\hline Variable & OR & $\mathrm{Cl} 95 \%$ & P value \\
\hline \multicolumn{4}{|l|}{ Unadjusted } \\
\hline Non hypertension & \multicolumn{2}{|c|}{ Reference } & - \\
\hline Hypertension & 2.13 & $2.03-2.24$ & $<0.001$ \\
\hline \multicolumn{4}{|l|}{ Adjusted $^{1}$} \\
\hline Non hypertension & \multicolumn{2}{|c|}{ Reference } & - \\
\hline Hypertension & 1.18 & $1.11-1.25$ & $<0.001$ \\
\hline ratio. & $\mathrm{Cl}:$ & confidence & interval. \\
\hline \multicolumn{4}{|c|}{$\begin{array}{l}{ }^{1} \text { This model was adjusted for age, sex, diabetes, chronic obstructive } \\
\text { pulmonary disease, obesity, pneumonia, smoking history, and other } \\
\text { cardiovascular diseases. }\end{array}$} \\
\hline
\end{tabular}

Copyright (c) 2021 by Author/s and Licensed by Modestum. This is an open access article distributed under the Creative Commons Attribution License which permits unrestricted use, distribution, and reproduction in any medium, provided the original work is properly cited. 
Our findings suggest that hypertension could be associated with a greater likelihood of immunosuppression in Mexican patients with SARS-CoV-2 infection. Hypertensive changes are associated with chronic inflammation that not only triggers endothelial dysfunction, but production of reactive oxygen species [5]. A baseline pro-inflammatory context may increase the risk of immunosuppression in COVID-19 patients.

Hypertension accounts up to $40 \%$ of cases worldwide, and it is associated with lethal disease, especially in developing countries [5]. Consequently, care prioritization of infected patients at higher risk of complications, such as hypertensive patients, is necessary to reduce inflation of deaths. Finally, it is recommended further research in pathways that justify the association between hypertension and immunosuppression in COVID-19 patients.

Author contributions: DCM: Conceptualization; Data curation; Formal analysis; Funding acquisition; Investigation; Methodology; Project administration; Resources; Software; Supervision; Validation Visualization; Roles/Writing - original draft; Writing - review \& editing. IPCC: Formal analysis; Writing - review \& editing.

Funding: No funding source is reported for this study.

Declaration of interest: No conflict of interest is declared by authors. Acknowledgements: DCM thanks Mexican Government for data release.

\section{REFERENCES}

1. Coronavirus Resource Center, Johns Hopkins University Maps \& trends. Available at: https://coronavirus. jhu.edu/map.html (Accessed 23 September 2020).

2. Yang J, Zheng Y, Gou X, Pu K, Chen Z, Guo Q, et al. Prevalence of comorbidities and its effects in patients infected with SARS-CoV-2: a systematic review and metaanalysis. Int J Infect Dis. 2020;94:91-5. https://doi.org/ 10.1016/j.ijid.2020.03.017 PMid:32173574 PMCid: PMC7194638

3. Verdecchia P, Angeli F, Reboldi G. Angiotensin-converting enzyme inhibitors, angiotensin II receptor blockers and coronavirus. J Hypertens. 2020;38(6):1190-1191. https://doi.org/10.1097/HJH.0000000000002469 PMid:32371811 PMCid:PMC7236844

4. Zhang $X, Y u$ J, Pan L, Jiang H. ACEI/ARB use and risk of infection or severity or mortality of COVID-19: A systematic review and meta-analysis. Pharmacol Res. 2020;158: 104927. https://doi.org/10.1016/j.phrs.2020.104927 PMid: 32422341 PMCid:PMC7227582

5. Tanase DM, Gosav EM, Radu S, Ouatu A, Rezus C, Ciocoiu M, et al. Arterial Hypertension and Interleukins: Potential Therapeutic Target or Future Diagnostic Marker? Int J Hypertens. 2019;2019:3159283. https://doi.org/10.1155/ 2019/3159283 PMid:31186952 PMCid:PMC6521461 